\title{
Electronic Line-Shafting Control for Paper Machine Drives
}

\author{
M. Aníbal Valenzuela and Robert D. Lorenz, Fellow, IEEE
}

\begin{abstract}
The current synchronized motion control methods used in paper machine drives are not designed to possess the inter-shaft stiffness properties which were responsible for the coordinating force inherent in classical, mechanically coupled paper machines. Consequently, these controllers cannot easily maintain coordination for all operating conditions. This paper presents the application of an "electronic line-shafting" control technique which serves to replicate and even improve on the historical, mechanical line-shafted properties. This technique was tested on a four-shaft experimental setup to evaluate such control during periods of drive-limited torque as well as sectional drive load disturbances. The experimental results demonstrate that the "electronic line-shafting" technique significantly improves the coordination, robustness, and overall stability of paper machine drives subjected to realistic physical limitations.
\end{abstract}

Index Terms-Multi-axis synchronization, paper machine control, relative stiffness control, virtual line-shaft control.

\section{INTRODUCTION}

$\mathbf{L}$ ONG AGO, early paper machine drives were constructed with mechanical interconnection components that produced motion with respect to a common line-shaft input. The mechanical power was produced by a single motor driving a line shaft to which all of the in-shafts were attached.

Fig. 1 shows a simplified arrangement of a line-shaft drive. It consists of a speed-controlled motor driving a long shaft all the way along the different mechanical sections. Each section is coupled to the line shaft through a gear box, conical pulleys, and the section connecting shaft. Conical pulleys allow draws to be set in the different mechanical sections. Assuming no belt slip in the conical pulleys, this mechanical arrangement assures that all the system shafts will remain rigidly locked to each other through the common line shaft, even in the presence of disturbances on individual sections. The only steady-state relative motion is due to torsional windup of shafts transmitting the driving torque.

Paper PID 00-27, presented at the 2000 IEEE Pulp and Paper Industry Conference, Atlanta, GA, June 19-23, and approved for publication in the IEEE TRANSACtions ON INDUSTRY APPLICATIONS by the Pulp and Paper Industry Committee of the IEEE Industry Applications Society. Manuscript submitted for review June 23, 2000 and released for publication October 19, 2000. This work was supported by the Consolidated Papers Foundation.

M. A. Valenzuela is with the Department of Electrical Engineering, University of Concepción, Concepción, Chile (e-mail: avalenz@die.udec.cl).

R. D. Lorenz is with ISEA-The Power Electronics and Drives Institute, Technical university of Rhein-Westfalen, 52066 Aachen, Germany, on leave from the Department of Mechanical Engineering and Department of Electrical and Computer Engineering, University of Wisconsin, Madison, WI 53706 USA (e-mail: lorenz@engr.wisc.edu).

Publisher Item Identifier S 0093-9994(01)00909-4.
As advances in power electronics and high-performance drives became available, the line-shaft structure evolved into modern, individual dc and ac sectional drives, which allow an increase in the operating speed and sectional power of paper machines. Fig. 2 shows a simplified arrangement of a sectional drive. Each mechanical section is driven by a fully controlled drive (some sections might have more than one). All the sectional drives are "electronically synchronized" through the master reference command, and the draws are set adding an auxiliary signal to the master reference. During a load disturbance in such a system, the speed in the disturbed section will decrease momentarily until the drive control is able to restore it to the reference speed. During this transient period, the loss of synchronization might cause a web break.

Therefore, although the increased power and flexibility allowed by sectional drives provided enormous strides in paper manufacturing, it lost the inter-shaft state feedback inherent to the line-shafted drives which was the driving force for the coordination of the multiple mechanical sections. Its properties are not achieved by the sectional drive control topology currently in use.

In [1], Lorenz and Schmidt showed that, by intentionally cross coupling different driven axes with electronic shafts stiffness and electronic shaft damping, synchronized motion control could be improved. In [2], the authors presented an enhanced electronic line-shafting control specialized for a filament winding machine [6]. This paper extends this new control method to the drive of paper machines, adding the capability of handling severe load disturbances and sustained drive saturation, without lack of relative synchronization.

\section{ELECTRONIC LINE-SHAFTING CONTROL}

Electronic line-shafting control is based on emulating and enhancing the desirable properties of the physical line-shaft driven mechanical system. Fig. 3 shows the block diagram for the system of Fig. 1. The main blocks of this system are the line-shaft drive, the physical connecting line shaft, the gear box and conical pulleys, the in-shafts, and the mechanical section rolls and load.

The detailed model of each block is presented in [3]. The physical line-shaft drive is modeled as a speed-regulated prime mover, and the physical connecting shaft model includes shaft stiffness and damping terms. The output (transferred) torque is produced by these terms. This output torque is applied to the follower drives as the driving torque and is reflected back to the line-shaft drive as load torque "feedback." These two paths are responsible for the robust physical synchronization between the line-shaft machine and the follower drives. It is these fun- 


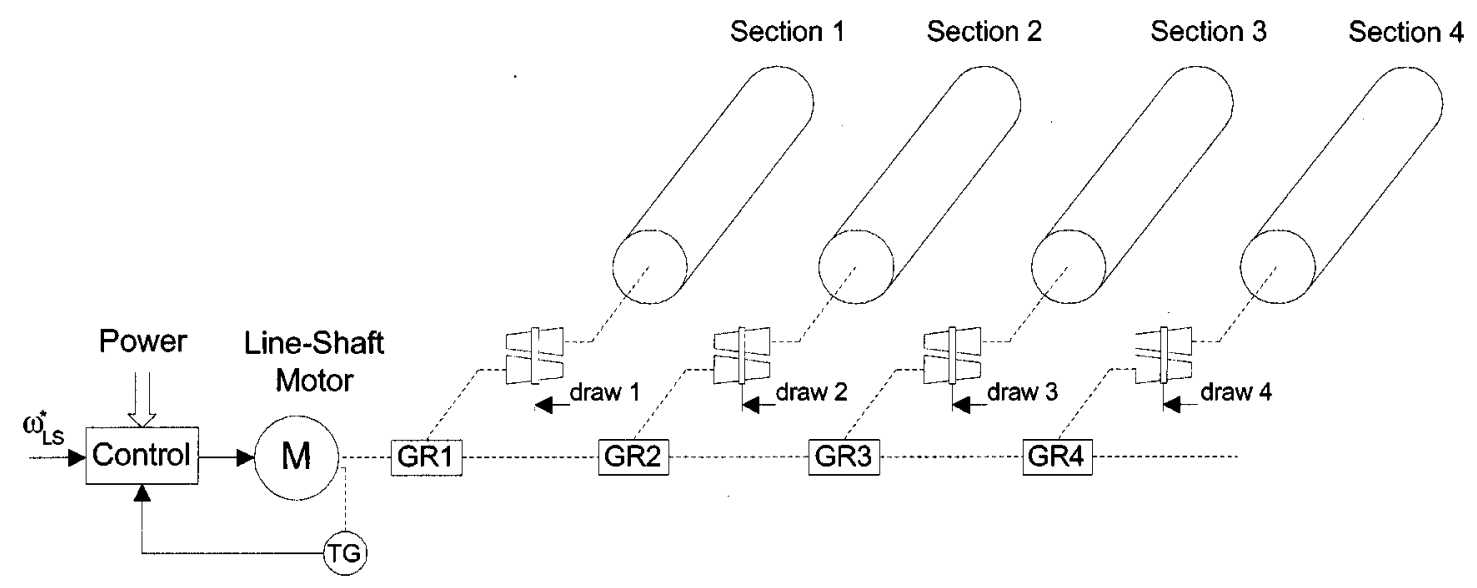

Fig. 1. Line-shaft drive system.

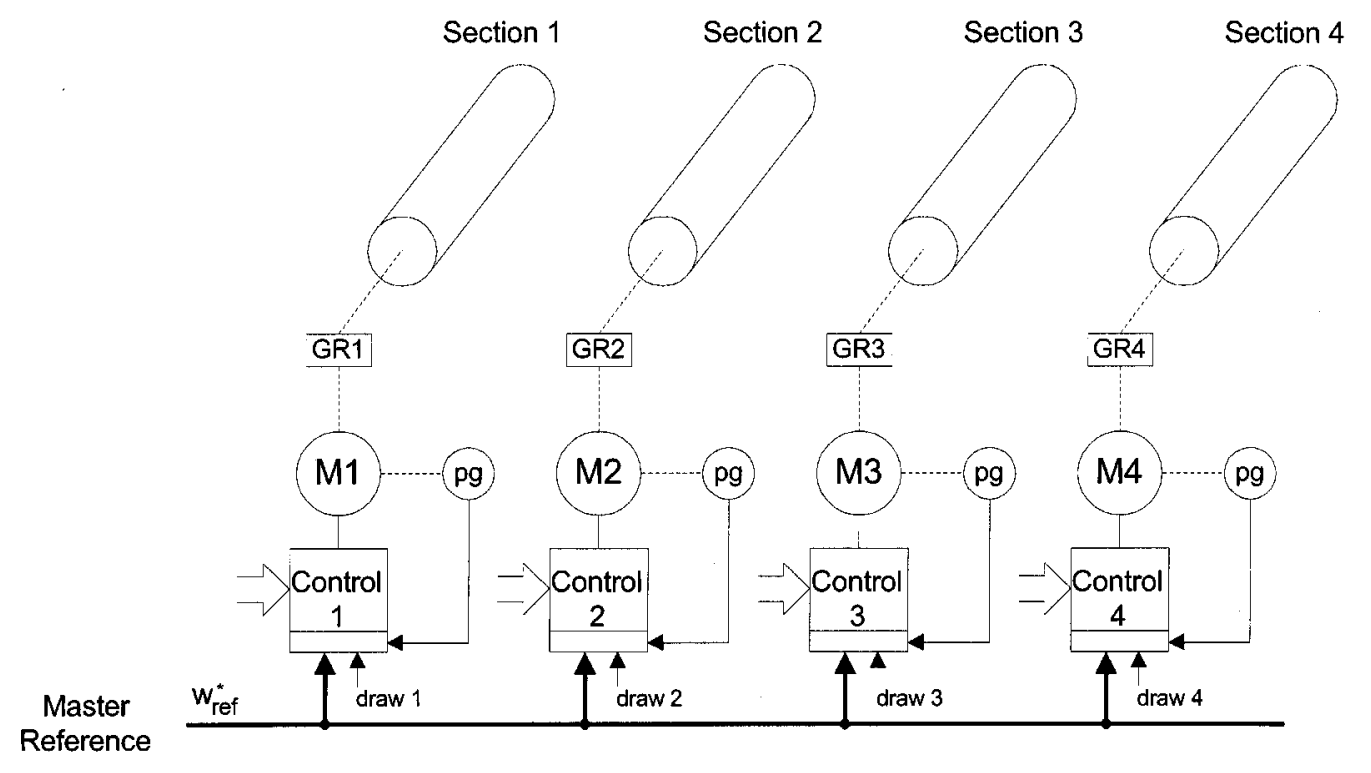

Fig. 2. Sectional drive system.

damental features which are emulated and enhanced in the new topology.

Fig. 4 shows the block diagram of the proposed control structure. This control structure replicates the mechanical line shaft machine of Fig. 3. It contains "a virtual line-shaft drive," "virtual in-shafts," and "virtual gear-box conical pulleys " combinations to replicate ideal physical elements. In order to obtain the simplest model, the line shaft has been assumed perfectly stiff, and only the in-shafts' stiffness and damping attributes are considered.

The physical line-shaft drive can be described as a virtual master reference that sets the instantaneous position $\left(\theta_{v}\right)$ and velocity $\left(\omega_{v}\right)$ references to the sectional drives. Since the virtual line-shaft drive (master reference) is not physical, the values of $\mathrm{J}_{v}$ and $\mathrm{b}_{a v}$ are relatively unconstrained control variables that are set to accomplish the desired dynamic performance with feasible trajectories to the follower drives.

The virtual compliant connecting in-shafts establish the basic relative state feedback needed to force the master reference to slow down or to speed up according to the load changes in the mechanical sections. Thus, these virtual in-shafts provide the coordination needed for relative motion control during load disturbances.

A critical difference between the mechanical line-shafted system and the proposed electronic line-shafting control for sectional drives arises from different physical limits. The synchronization limit of the mechanical line-shafted system is the torque capacity of the line shaft and in-shafts (or slip of the conical pulleys). The torque capacity of the mechanical shafts was generally far in excess of the torque needed for even worst case loading scenarios. By comparison, the distributed sectional drives are limited by torque and/or velocity limits of the drives. Peak torque limits of modern drives are generally only a factor of $2 \times$ above the rated torque. This rather low limit makes sustained operation in torque limits a very important issue.

If a sectional drive hits a torque limit and begins to fall behind the line-shaft reference, the electronic line-shafted system automatically increases the torque reflected back to the virtual line shaft. This torque feedback causes the line shaft to decelerate, which, in turn, causes all drives to decelerate to keep synchronized to the limited drive. 


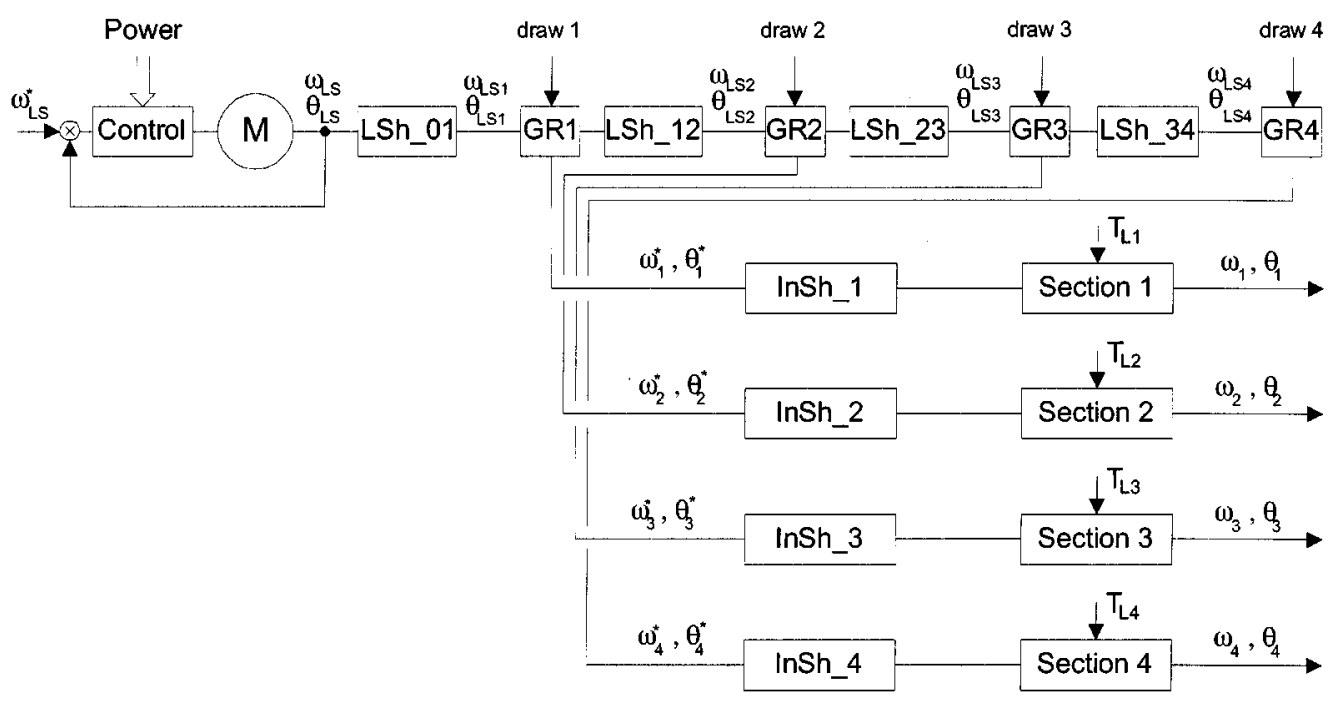

LSh_ij : Line-shaft between section " $i$ " and section " $j$ "

InSh_i : In-shaft of section " $i$ "

Fig. 3. Block diagram of line-shaft system.

\section{EXPERIMENTAL SETUP}

Experimental evaluation of the proposed electronic line-shafting control algorithm was performed in the four-section mechanical setup of Fig. 5. The hardware implementation of the control algorithms uses a 486-DX2 personal computer with three dedicated cards: a digital signal processor (DSP) card based in the 32-bit-40-MHz, TMS320c30 processor; a 16-bit $200-\mathrm{kHz}$ A/D-D/A card; and a 16-bit counter card. The counter card is fitted with 20 counters, a $5-\mathrm{MHz}$ clock, and is directly controlled by the personal computer which counts the pulses coming from the motor encoders. The DSP processor executes the speed estimator algorithms [5] and the electronic line-shaft control routines. Also, it generates the control voltages to each of the torque-controlled drives using the $\mathrm{A} / \mathrm{D}-\mathrm{D} / \mathrm{A}$ card.

\section{EXPERIMENTAL EVALUATION}

Electronic line-shafting control has been designed to properly handle abnormal or transient conditions that might produce loss of synchronization between the axes. When applied to paper machines drives, the benefits of this new control topology will show up during operation under torque and/or speed limits of any sectional drive, and during load disturbances in any mechanical section.

Paper machine sections are not subjected to severe load disturbances. Nevertheless, torque limiting might occur while ramping up (or down) the mechanical sections if a sectional drive did not have enough peak torque to accelerate the inertia at the desired ramp rate.

To establish a correct baseline condition, operation was first tested in a low-inertia section of the experimental setup. The section load is initially $78 \%$ of the drive's rated torque and the $5 \% \mathrm{ramp}$ is set to a ramp rate of $1.26 \mathrm{rad} / \mathrm{s}^{2}$. Under these conditions, the current increased up to about $82 \%$, which is below the current limit, and all the sections followed the $5 \%$ ramp master reference as shown in Fig. 6.

The same condition was tested in a high-inertia section 2 of the experimental setup. The current limit arbitrarily was set to $98 \%$. Under these conditions, the current limit in section 2 is reached, and it is no longer capable of following the 5\% ramp master reference and, thus, could lose synchronization. The results are shown in Fig. 7. It can be seen that when section 2 reaches its current limit and begins to lag, the virtual line shaft also slows down as it is forced by the feedback torque from the section 2 shaft to a speed that can be followed by the section 2 drive. Thus, the virtual command to the other drives, $\omega_{V}$, decreases to a trajectory that can be followed by the section 2 drive. As a consequence, all the sections follow this modified reference trajectory and maintain synchronized motion.

In the same situation in a conventional sectional drive, the master reference will continue ramping up, and all the other drives except section 2 will follow this reference and, therefore, the paper web in section 2 will break.

Another interesting condition in which the electronic lineshafting control can show its beneficial features is during load disturbances. Fig. 8 shows the response of the system when a step load disturbance is applied to section 2. Initially, the section load is about $58 \%$ of rated torque, and the load disturbance increased it to about $92 \%$. As a consequence, the velocity of section $2, \omega_{2}$, decreases. The resulting torque reflected back to the virtual line-shaft drive causes it to slow down, which causes the virtual command $\omega_{v}$ to also decrease to a value for which synchronism can be maintained.

Again, electronic line shafting forces all sections to maintain synchronization with the disturbed section. After approximately $7.5 \mathrm{~s}$, the load disturbance is released and the system again keeps all the sections synchronized. It should be noted that, because the electronic line shaft control applies torque (current) to all of 


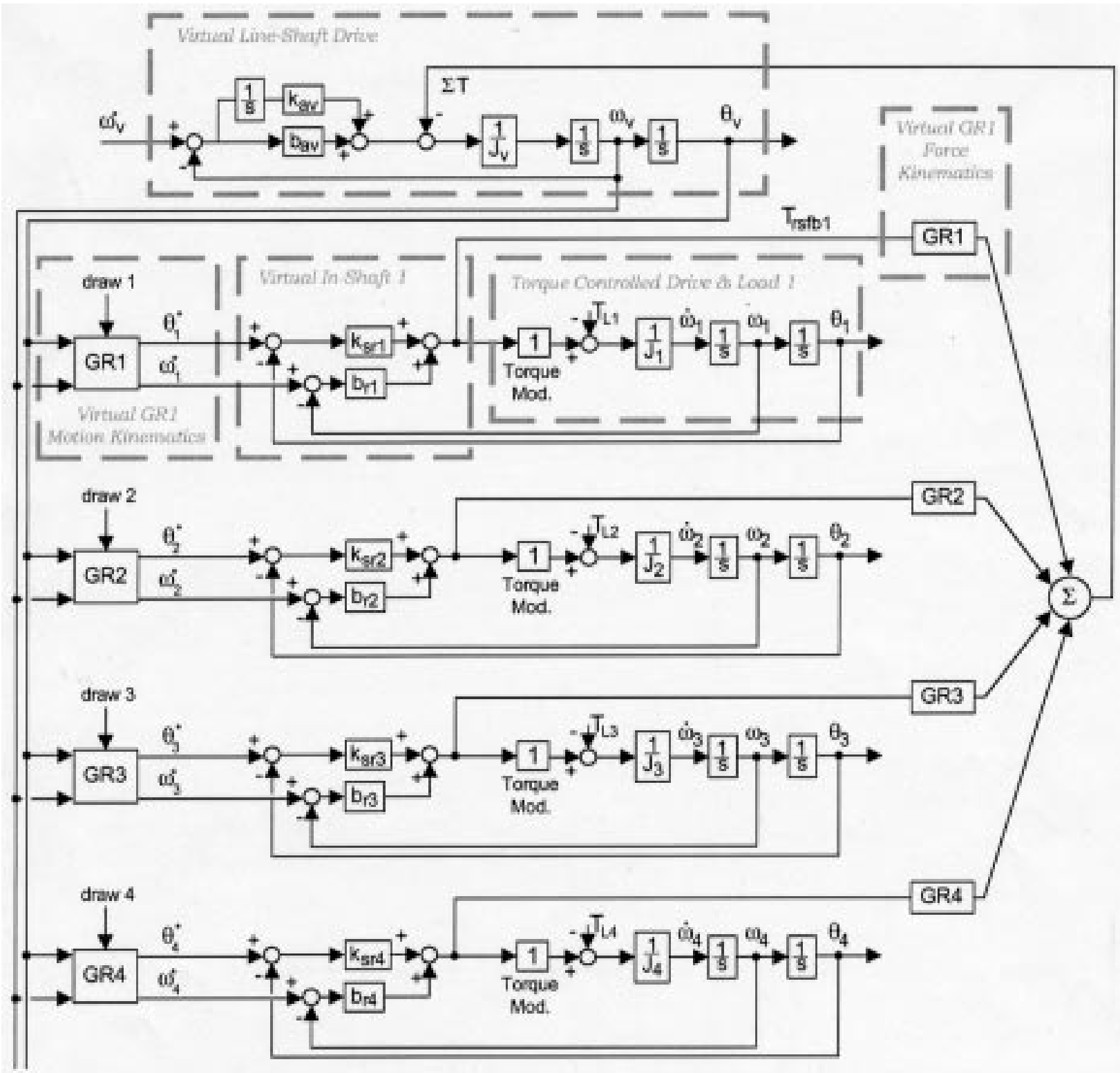

Fig. 4. Block diagram of the electronic line-shafting control topology.

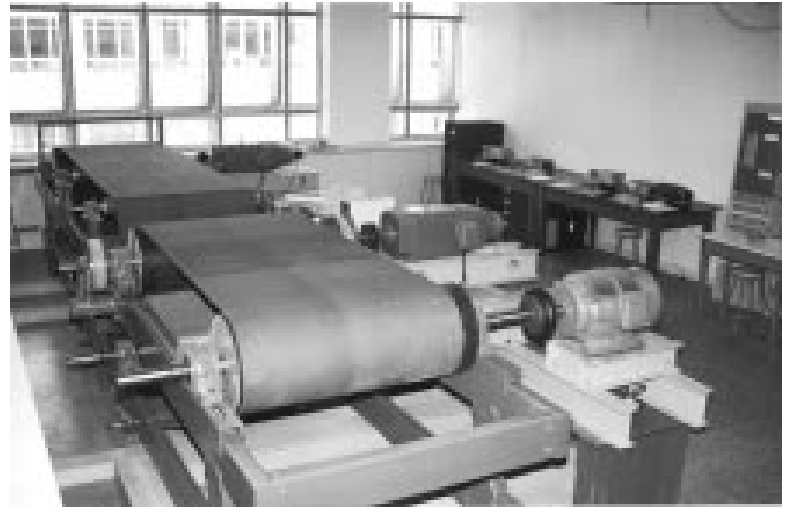

Fig. 5. Experimental setup.

the drives, the system response to loads is fast and the angular error is kept very low.

\section{CONCLUSIONS}

Electronic line-shafting control has been developed to emulate the inter-shaft stiffness inherent to classical line-shaft drives. It is thus inherently capable of maintaining synchronization between the axes during startup and shutdown and even during extreme or abnormal load conditions.

Unlike its mechanical counterparts, electronic line-shaft control allows the designer to effectively apply well-damped "electronic" shafts which do not cause resonance problems in the system and inherently provide well-damped section-to-section dynamics.

This feature provides a very attractive secondary benefit. It is quite well known in machine controls that "soft," i.e., lowbandwidth, servo control tends to provide smoother machine operation than "hard," i.e., high-bandwidth servo control. By providing well-behaved section-to-section dynamics, electronic line-shafting diminishes the need for individual drive hard servo 


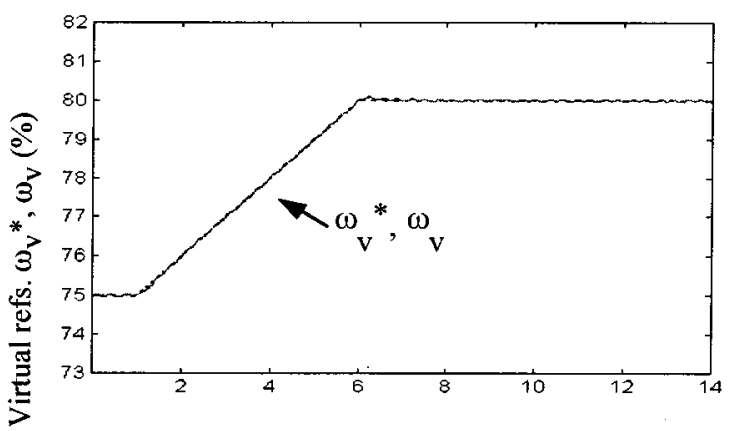

Time (s)

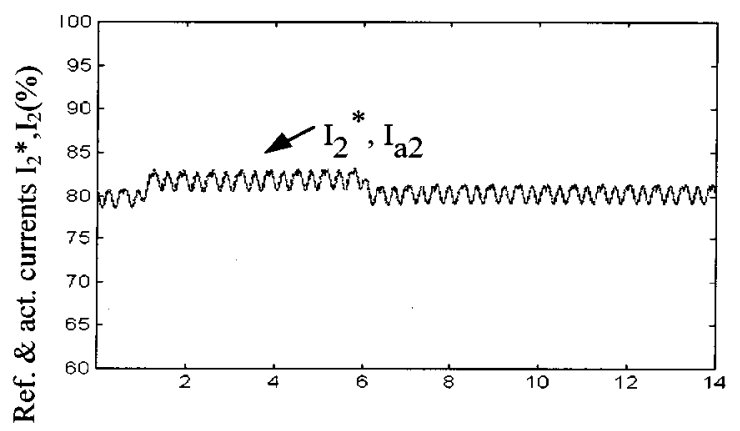

Time (s)

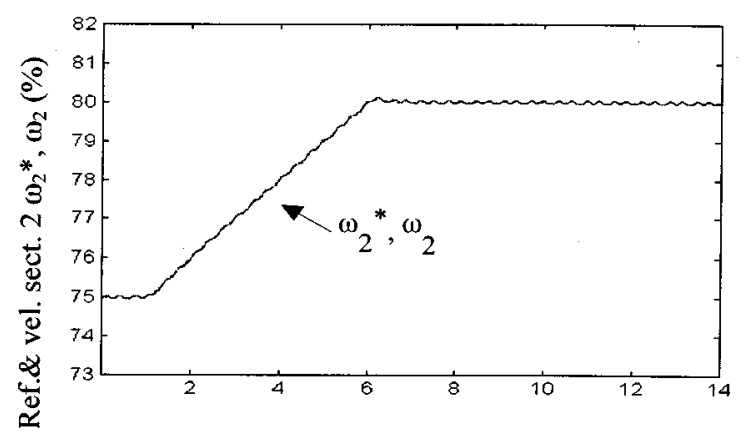

Time (s)

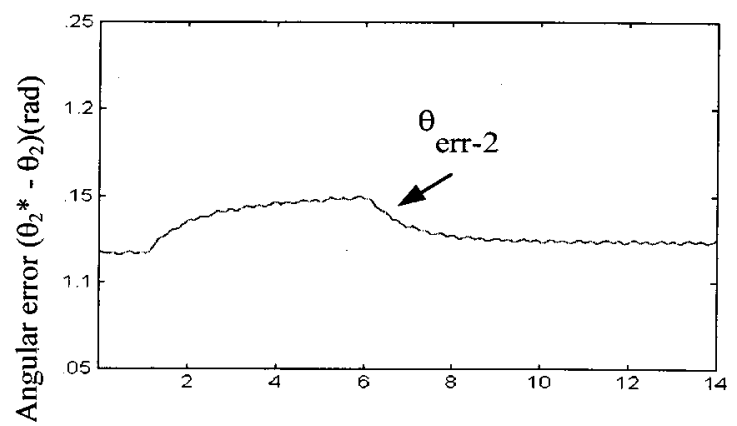

Time (s)

Fig. 6. Evaluation during acceleration from $75 \%$ to $80 \%$ speed without torque (current) limiting.

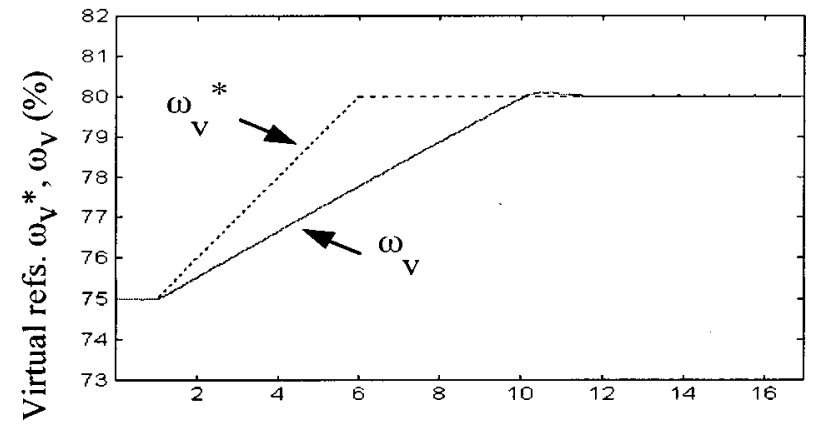

Time (s)

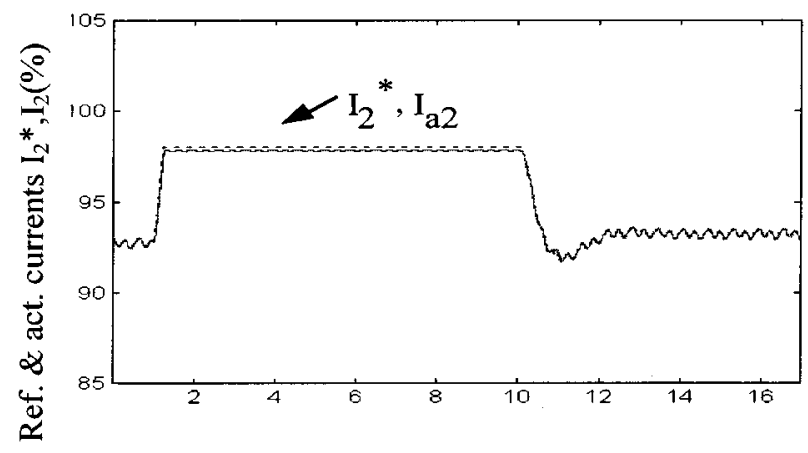

Time (s)

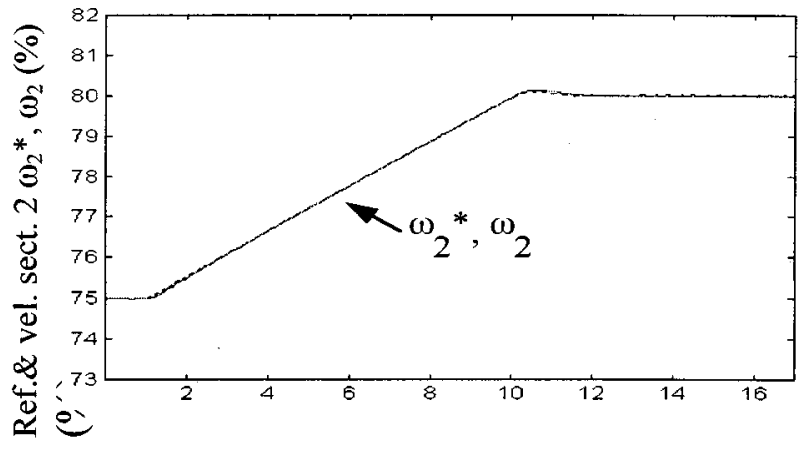

Time (s)

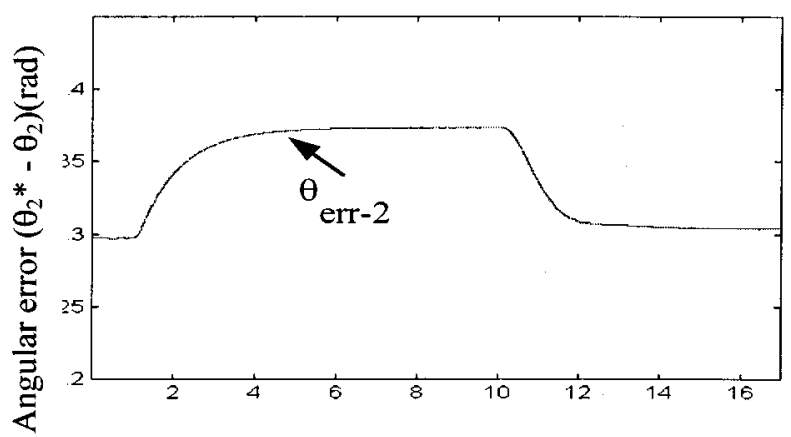

Time (s)

Fig. 7. Evaluation during acceleration with torque (current) limiting in section 2.

control. This could prove to be a major secondary benefit with significant process yield payback.
In paper machine drives, this control topology allows the drive system to handle torque and speed limits in any sectional 


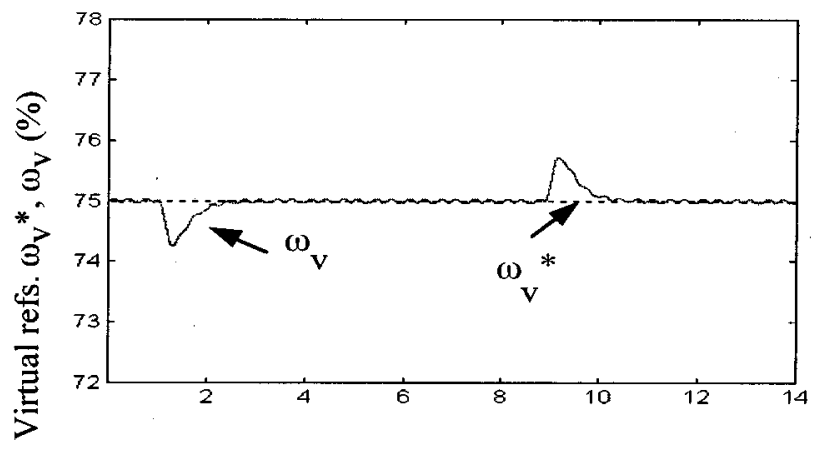

Time (s)

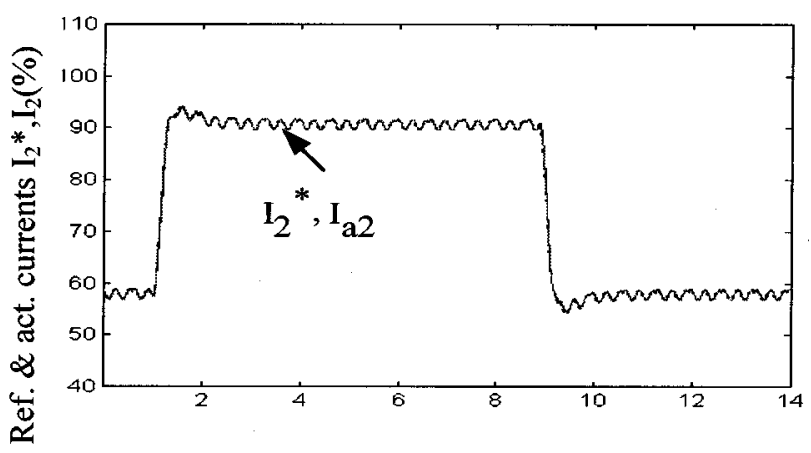

Time (s)

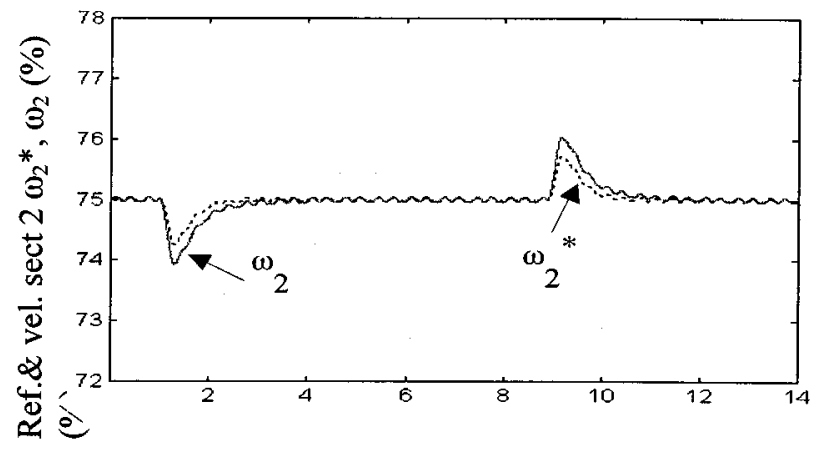

Time (s)

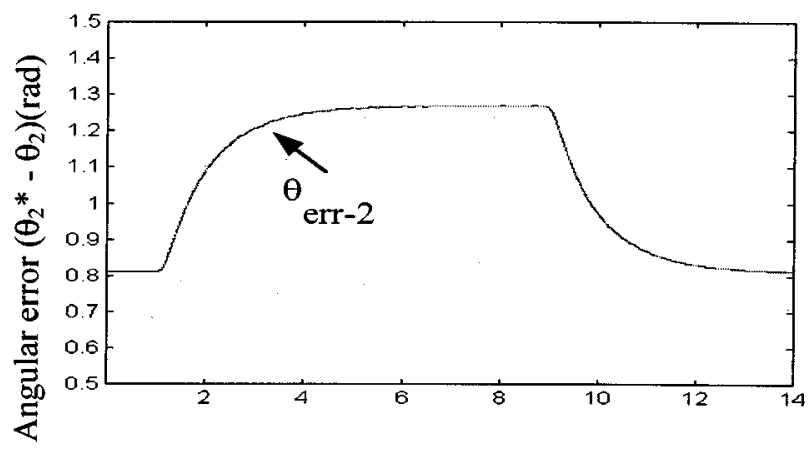

Time (s)

Fig. 8. Evaluation during a step load disturbance.

drive, and load disturbances in any section. Both situations were evaluated in a four-section experimental machine setup.

In addition to the well-behaved disturbance-handling properties that can be achieved, electronic line-shafting control also demonstrates fast response to loads due to its inherently direct "torque-controlled" operation.

The experimental results demonstrate that this control can effectively handle sectional drive current (torque) limits and load disturbances in any sectional drive, maintaining synchronized motion between the different mechanical sections.

Use of electronic line-shafting control in paper machine drives could provide significant strides to the machine capabilities, comparable to those obtained when the sectional drive replaced the mechanical line-shaft system.

This approach will make the machine less sensitive to mismatched controller tuning since the electronic relative stiffness and damping will dominate the dynamics.

Electronic line shafting will make the machine less sensitive to improper ramp rate settings or draw signals. Startup and shutdown synchronization can, thus, be maintained. As a consequence, web breaks could be greatly reduced while allowing full utilization of the machine drive capabilities.

\section{ACKNOWLEDGMENT}

The authors wish to acknowledge the motivation provided by the Wisconsin Electric Machines and Power Electronics Consortium (WEMPEC) of the University of Wisconsin, Madison.

\section{REFERENCES}

[1] R. D. Lorenz and P. B. Schmidt, "Synchronized motion for process automation," in Conf. Rec. IEEE-IAS Annu. Meeting, 1989, pp. 1693-1699.

[2] R. G. Anderson, A. J. Meyer, M. A. Valenzuela, and R. D. Lorenz, "Web machine coordinated motion control via electronic line-Shafting," in Conf. Rec. IEEE-IAS Annu. Meeting, 1999, pp. 300-306.

[3] R. G. Anderson, "Coordinated motion control of multi-axis machines via electronic line shafting," M.S. thesis, Dept. Mech. Eng., Univ. Wisconsin, Madison, Sept. 1994.

[4] A. J. Meyers, "Design and implementation of a multiprocessor control system for a multi-axis, cross coupled machine control," M.S. thesis, Dept. Elect. Comput. Eng., Univ. Wisconsin, Madison, Dec. 1994.

[5] R. D. Lorenz and K. Van Patten, "High resolution velocity estimation for all digital, AC servo drives," IEEE Trans. Ind. Applicat., vol. 27, pp. 701-705, July/Aug. 1991.

[6] R. G. Anderson, R. D. Lorenz, and A. J. Meyer, "Method for coordinating motion control of a multiple axis machine," U.S. Patent 5659480 , Aug. 1997.

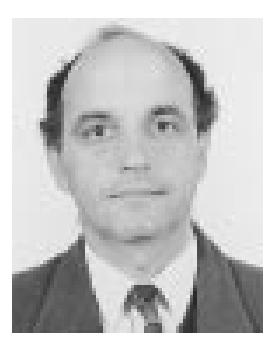

M. Aníbal Valenzuela received the Electrical Engineering degree and the Magister degree in electrical engineering from the University of Chile, Santiago, Chile, in 1976 and 1978, respectively.

Since 1978, has been with the Department of Electrical Engineering, University of Concepción, Concepción, Chile, where he is currently an Associate Professor in the area of electric machines and drives. His research is focused on motion control of industrial drives and coordinated motion of multi-axis systems. 


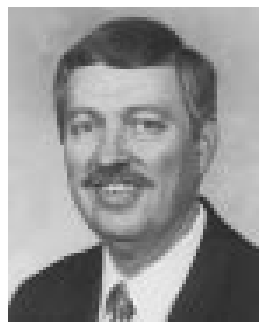

Robert D. Lorenz (M'84-SM'91-F'98) received the B.S., M.S., and Ph.D. degrees from the University of Wisconsin, Madison, in 1969, 1970, and 1984 respectively.

Since 1984, he has been a member of the faculty of the University of Wisconsin, Madison, where he is the Consolidated Papers Foundation Professor of Controls Engineering in both the Mechanical Engineering and Electrical and Computer Engineering Departments. In this position, he acts as Co-Director of the Wisconsin Electric Machines and Power Electronics Consortium. He is also an active consultant to many organizations. He was a Visiting Research Professor in the Electrical Drives Group, Catholic University of Leuven, Leuven, Belgium, in the summer of 1989 and in the Power Electronics and Electrical Drives Institute, Technical University of Aachen, Aachen, Germany, in the summers of 1987, 1991, 1995, 1997, and 1999. In 1969-1970, he conducted his M.S. thesis research at the Technical University of Aachen. From 1972 to 1982, he was a member of the research staff at the Gleason Works, Rochester, NY. His current research interests include sensorless electromagnetic motor/actuator technologies, real-time signal processing and estimation techniques, precision multi-axis motion control, and ac drive and high-precision machine control technologies.

Dr. Lorenz is currently the IEEE Industry Applications Society (IAS) Vice President/President Elect, a Distinguished Lecturer of the IAS for 2000/2001, the immediate Past Chair of the IAS Awards Department, and past Chairman of the IAS Industrial Drives Committee. He is a member of the IAS Industrial Drives, Electrical Machines, Industrial Power Converter, and the Industrial Automation and Control Committees. He is a member of the IEEE Sensor Council AdCom and the IEEE Neural Network AdCom. He is a Registered Professional Engineer in the States of New York and Wisconsin. He is also a member of the American Society of Mechanical Engineers, Instrument Society of America, and Society of Photo-Optical Instrumentation Engineers. 